\title{
Desafios éticos e políticos no vídeo Vida Estelita, subjetividades políticas em devir ${ }^{1}$
}

\author{
Cristina Teixeira Vieira de Melo
}

Resumo: Vida Estelita é um registro memorialístico da ocupação do Cais José Estelita, em Recife, em meados de 2014. Os entrevistados falam não apenas da luta pelo terreno, mas do desejo de novas formas de vida. Os realizadores excluíram da edição final trechos dos depoimentos em que os jovens, ao confrontarem a ordem estabelecida, se expunham mais fortemente. Neste contexto, Vida Estelita reabre a discussão sobre a ética no documentário: como representar o outro? Como fazê-lo de maneira a não diminuir a sua potência? Como não camuflar as formas de vida em luta? Esses dilemas éticos acentuam-se no caso de um cinema militante em que "o filme que se queria fazer se contrapõe aquele que deveria ser feito".

Palavras-chave: cinema militante; \#OcupeEstelita; ética; memória; entrevista.

Abstract: Ethical and political challenges on the video Vida Estelita: political subjectivities in becoming - Vida Estelita is a memorialist record of the Cais José Estelita occupation in 2014, which took place in the city of Recife, Pernambuco. The interviewees talk not only about the fight for the territory but also about their desire for new forms of life. The filmmakers have edited to the final cut some youngsters' testimonies actively exposing themselves when confronted with the established order. In this context, Vida Estelita reopens the discussion on ethics in the documentary: how to depict other people? How is it possible to do that without diminishing their potentials? How to not camouflage those struggling forms of life? These ethical dilemmas grow bigger in the case of militant cinema in which "the film wanted to be done opposes that one that should be done".

Keywords: militant cinema; \#OcupeEstelita; ethics; memory; interview.

\section{Da genealogia do Movimento Ocupe Estelita}

Em 2008, cerca de 10 hectares no Cais José Estelita, em Recife, foi arrematado em leilão pelas construtoras Moura Dubeux, Queiroz Galvão, Ara Empreendimentos e

1 Uma versão inicial desse texto foi apresentada no Grupo de Pesquisa em Cinema, durante o XXXVIII Congresso Brasileiro de Ciências da Comunicação, realizado em 2015. 
GL Empreendimentos. Esse consórcio vislumbra construir no local um complexo imobiliário de alto padrão nomeado "Novo Recife". Quando a iniciativa veio a público, em 2012, a legalidade do leilão, o processo administrativo que levou à aprovação do projeto na Prefeitura do Recife (PCR) e os impactos socioambientais do empreendimento passaram a ser amplamente discutidos pela sociedade civil. O grupo Direitos Urbanos (DU), origem do Movimento Ocupe Estelita (MOE), surgiu nesse momento.

O espaço limitado deste artigo não permite detalhar a cadeia de ações judiciais, audiências públicas, ocupações e confrontos de rua deste imbróglio. Sem sombra de dúvida, um dos acontecimentos mais marcantes desta história ocorreu na manhã de 17 de junho de 2014 quando um batalhão da Polícia Militar chegou ao Cais a fim de fazer a reintegração de posse da área. Anteriormente, no dia 21 de maio, assim que o consórcio iniciou a demolição dos antigos armazéns de açúcar, um grupo de ativistas ocupou o local. A derrubada dos galpões teve que ser suspensa em função da ocupação. Em meio à luta política, os jovens acampados foram ensaiando uma vida em comunidade. Mesmo a violência da reintegração de posse não findou de vez a experiência do acampamento. Alguns ocupantes resolveram permanecer abarracados embaixo do viaduto Capitão Temudo, situado próximo do Cais, e só saíram de lá em 10 de julho. Foram, portanto, 51 dias de ocupação. Daquela época até hoje muita coisa aconteceu. A novidade mais recente, datada de 30 de setembro de 2015, é a investigação por parte da Polícia Federal de fraudes no leilão de 2008.

\section{Das condições de possibilidade de gravação}

Vida Estelita é uma espécie de roda de diálogo com sete dos jovens que permaneceram acampados embaixo do viaduto após a reintegração de posse. Um espectador ingênuo poderia supor que a ausência na superfície da imagem dos corpos e das vozes daqueles que filmam e conduzem as entrevistas tornaria o ato de filmar impessoal, podendo qualquer um está ali no comando. Terrível engano. Este alguém que está fora da imagem (mas não fora da cena) não poderia ser qualquer um. Os jovens não falariam para um qualquer.

Marcelo Pedroso e Pedro Severien² lembram que as entrevistas de Vida Estelita foram possíveis, em parte, porque durante a desocupação do terreno eles dois e Ernesto Carvalho tinham lutado e apanhado junto com os acampados. Até então, os ocupantes resistiam à presença de cinegrafistas no local. Isso se justificava porque, embora alguns integrantes da Brigada Audiovisual militassem há muito tempo no MOE, eles eram desconhecidos de parte dos jovens instalados no Cais. Nesse contexto, não havia garantias de que aqueles com câmeras na mão estavam comprometidos com as causas do Ocupe. Existia a desconfiança de que pudessem estar trabalhando para a grande mídia, antipatizada

2 Essa e outras informações nos foram fornecidas pelos realizadores Marcelo Pedroso e Pedro Severien durante entrevista realizada em 16/10/2014. Além deles, Ernesto de Carvallho e Ednéia Alcântara também assinam o vídeo. 
pelos manifestantes em decorrência de seu posicionamento contrário ao \#OcupeEstelita. Outro motivo de desconfiança advinha da relação pregressa dos realizadores com os integrantes do DU. Ainda que esta entidade tenha encabeçado os protestos contra o Novo Recife, no geral, não foram seus integrantes que permaneceram acampados, mas estudantes recém-chegados ao movimento. Existia uma divisão na condução política da ocupação: o DU se guiando por uma orientação mais jurídica e os acampados por uma ideologia mais anarquista. Por fim, a iconoclastia própria deste tipo de movimento dificultava as filmagens. A imagem do rosto colocava em risco os acampados, que poderiam vir a ser identificados e criminalizados.

\section{Do audiovisual como lugar de memória}

A professora Ednéia Alcântara, que já realizava pesquisas sobre resiliência em movimentos sociais, sugeriu a Pedro, Marcelo e Ernesto filmar uma roda de conversa com os jovens da ocupação. Tratava-se de tarefa necessária e urgente, pois, mediante a desintegração da ocupação aquela comunidade de experiência e afeto estava fadada a não mais existir, consequentemente, suas memórias também estavam ameaçadas, passariam para o plano da história.

Halbwachs (1990) sustenta que a história começa onde a memória acaba. Segundo ele, as condições necessárias para que exista memória são os sentimentos de pertencimento e continuidade presentes naquele que lembra. A memória "retém do passado somente, aquilo que ainda está vivo ou é capaz de viver na consciência do grupo que a mantém" (ibid, p.56). Ou seja, a memória não promove uma ruptura entre presente e passado, já a história fragmenta o tempo histórico e mantém uma relação de exterioridade e distanciamento em relação aos grupos. Para Halbwachs, outro aspecto importante da memória é seu caráter coletivo, as memórias de um indivíduo nunca são só suas, uma vez que nenhuma lembrança pode existir apartada da sociedade.

Pierre Nora, por seu turno, fala em "lugares de memória" (1993), pois, no instante em que um grupo desaparece, a única forma de salvar as lembranças é fixá-las por inscrito em uma narrativa. Ele afirma que os lugares de memória nascem e vivem do sentimento de que não há memória espontânea, portanto seria preciso "criar arquivos, manter aniversários, organizar celebrações, pronunciar elogios fúnebres, notariar atas, porque essas operações não são naturais. É por isso a defesa pelas minorias, de uma memória refugiada sobre focos privilegiados" (ibid, p.13).

Ao servir como um "lugar de memória" dos acampados, Vida Estelita configurase como contradiscurso à ordem do poder formada pelo Governo Estadual, Prefeitura, Consórcio Novo Recife e mídia hegemônica. Trata-se de um registro documental no qual não se busca, como no jornalismo, ouvir os dois lados de uma história, a escuta é assumidamente unilateral, partidária, militante. A necessidade de registrar o ponto 
de vista do \#OcupeEstelita responde à falta de notícias sobre o assunto na imprensa local. Apesar da importância histórica do acontecimento para a cidade pouco dele se comentou na mídia tradicional. Alguns denunciam inclusive que o projeto Novo Recife só pôde avançar porque, além de atender aos interesses da elite política e econômica do Estado, contou com o silêncio cúmplice da mídia local, dependente dos anunciantes privados e estatais. O esforço de toda a produção audiovisual do \#OcupeEstelita é justamente rachar a vocalização monocórdica da mídia hegemônica.

\section{Da entrevista como dispositivo}

O dispositivo fílmico diz respeito ao "conjunto de regras que organizam o filme impondo-lhe limites espaço-temporais, controles e descontroles" (MIGLIORIN, 2008, p. 2). Todo dispositivo pressupõe uma dimensão de controle, ditada pelas regras e limites estabelecidos pelo seu criador, e outra dimensão de abertura determinada pelas possibilidades de atuação e de interação entre os seus agentes. Entre permissões e interdições, "fechamento" (zonas de controle) e "abertura" (margem de liberdade), cada dispositivo aciona um universo interacional que depende não apenas das "regras", mas também das características dos agentes e da materialidade que ele assume. Em Vida Estelita a entrevista é o dispositivo que permite a construção da experiência, da memória e a própria elaboração de si como personagem.

Pedroso e Severien revelaram que inicialmente não se sentiram seduzidos pela proposta de Edinéia de gravar uma roda de conversa com os jovens acampados. Percebiam a importância memorialística de tal registro, mas resistiam justamente em relação ao emprego da entrevista. Não é difícil supor de onde vem essa resistência. Em Cineastas e imagens do povo, Bernardet (2003) aponta que embora o cinema direto tenha trazido à tela um universo verbal rico e até então desconhecido, a entrevista terminou se generalizando e as consequências estéticas, éticas e políticas foram várias e negativas. Se no início ela era uma tentativa de encontrar o outro, com o tempo, o entrevistado deixou de ser um interlocutor com quem se travava um diálogo e passou a ser um sujeito que estava ali para responder perguntas e ilustrar a tese do realizador, configurando o que o autor chamou de "modelo sociológico".

Os realizadores de Vida Estelita sabiam que a tentativa de construir uma memória social da ocupação via entrevista trazia em si o perigo de reduzir a voz de cada ocupante à do coletivo. Ou seja, as singularidades diversas corriam o risco de serem comprimidas numa identidade única: a do jovem militante em luta pelo redimensionamento do espaço público. Por outro lado, o filme que precisava ser feito em nome de um audiovisual engajado não era outro senão o do registro daquela experiência coletiva, o relato daqueles que, conjuntamente, lutaram pelo Estelita.

De fato, os realizadores não saíram ilesos desse ato de filmar o outro. No encontro com os jovens acampados, o mundo da vida, aliás, das multiplicidades de vida, produziu 
rasgos no projeto do filme militante a ser feito. Deparar-se com esse "excesso" condicionou dilemas éticos vividos na hora da montagem. Por ora, deixamos de lado as apreciações éticas e políticas sobre o processo de seleção que deixou de fora algumas cenas filmadas. Mais adiante retomamos este ponto.

\section{Da partilha do sensível}

Em Vida Estelita a disputa por uma nova configuração da cidade aparece enredada a experiências de vida marcadas pelo sentimento de exclusão, violência e preconceito. Os depoimentos transcritos abaixo deixam a mostra a existência de uma divisão entre um "nós" e um "eles", denunciam um tratamento desigual entre esses grupos e reivindicam a construção de um mundo mais igualitário. Os pronomes e verbos em 1ª pessoa ("eu", "me sentia") bem como o uso de modalizadores de intensidade ("muito", "sempre") acentuam a forma como esses sujeitos estão implicados naquilo que narram.

Me sentia muito excluída da minha cidade, eu sempre me sentia assim, desde criança.

Na Brasília Teimosa, eu vivi, minha mãe viveu dentro dessa luta intensa de construir um barraco, eles vir derrubarem. [...] até hoje essa luta existe, entendeu?

A gente já é excluído por ser negro, a gente já excluído por ser gay, a gente já é excluído por ser pobre, já é excluído por ser bolsista da universidade; por várias coisas e a gente não tem voz na nossa cidade e o que me motiva tá aqui todos os dias é vê todas essas pessoas tentando fazer desse espaço um espaço onde realmente a gente seja ouvido, onde realmente este povo excluído diga a gente tá aqui, a gente tem voz, a gente quer modificar a cidade, a gente quer participar das decisões que constroem a nossa cidade.

Impossível se deparar com estas falas sem lembrar da forma como política e estética se vinculam na obra de Rancière, em especial no seu conceito de "partilha do sensível": "sistema de evidências sensíveis que revela, ao mesmo tempo, a existência de um comum e dos recortes que nele definem lugares e partes respectivas" (2005, p.15). A visão de Rancière sobre estética é ampla: "recorte dos tempos e dos espaços, do visível e do invisível, da palavra e do ruído que define ao mesmo tempo o lugar e o que está em jogo na política como forma de experiência" (ibid, p.16). Pensar o comum associando-o à ideia de partilha do sensível significa abordá-lo como um modo de repartição desigual entre iguais, o que aponta a dimensão política aí existente.

Rancière estabelece duas formas de partilha do sensível, opostas em seu princípios e entrelaçadas em seu funcionamento: polícia e política. A ordem policial é hierárquica, nela os corpos estão designados por seu nomes para ocupar lugares e tarefas já determinados. 
Já a política se dá quando a lógica policial, responsável pelas partilhas desiguais e tida como supostamente natural, é perturbada por lutas que visam a atualização do princípio da igualdade. A política, portanto, funda-se na encenação de um dano.

Importante frisar que a política não tem lugar próprio, ela não existe fora da polícia. A irrupção da política provoca a transformação da ordem policial, mas não seu desaparecimento. Aliás, para Rancière, toda política enfrenta o perigo de ser incorporada à polícia, anulando-se no campo dos consensos estabelecidos. Nesse sentido, uma comunidade dissensual não busca o entendimento, mas tornar evidente um desacordo. Seu caráter é polêmico e litigioso.

\section{Dos processos de subjetivação}

Da mesma forma que a política não tem lugar próprio, a expressão "sem-parte" (RANCIÉRE, 1996) não designa um grupo empírico. Os "sem-parte" não existem previamente a encenação do dano. Eles são fruto de um processo de subjetivação política que se dá no ato de criação da cena polêmica. Por isso, o sujeito político não equivale meramente àquele que toma consciência de si, mas àquele que se torna um agente do dissenso.

Mais acima, vimos como os entrevistados de Vida Estelita atrelaram a luta pela cidade a uma experiência de exclusão e violência encarnada em seus corpos. Já no depoimento abaixo transcrito, a motivação para resistir e lutar baseia-se numa lógica mais racional do que vivencial. O entrevistado incorpora o argumento de autoridade de que a geografia humana do Cais, área historicamente habitada por "comunidades", não deve se prestar à construção de um conglomerado de prédios de luxo. No enunciado "a gente vem numa área histórica [...] e pergunta a ela o que ela quer ser", ao mesmo tempo em que a expressão "a gente" aproxima o sujeito que enuncia das causas do Estelita, o verbo "vir" indicia que o enunciador precisa se deslocar de um outro local para estar ali. Paralelamente, o fato de se referir ao Estelita em $3^{\text {a }}$ pessoa ("pergunta a ela...") reforça ainda mais esta percepção de distanciamento. ${ }^{3}$

Uma coisa que é um consenso aqui, pelo menos dentro da ocupação, é o que não se quer pro Estelita. Que é esse modelo de cidade imposto de cima pra baixo. E a partir do momento que a gente tem o poder de negar isso, a gente não quer isso, a gente pode construir o que a gente realmente quer pro Estelita. Primeiro, a gente pode perguntar pro Estelita o que ele quer ser. E a gente vem numa área histórica da cidade, que está rodeada de comunidades, e aí você pergunta a essa área

3 A interpretação aqui sugerida não deve levar a entender que a concepção adotada neste trabalho é a de que a língua é um reflexo direto da realidade. As falas dos sujeitos não estão sendo tomadas em uma relação direta com o lugar que ocupam no mundo. São indícios da formação discursiva (FD) a qual pertencem. Vale lembrar que uma FD é sempre heterogênea a ela mesma, pois regida pelo interdiscurso. "A unidade de uma formação discursiva não é a manifestação majestosamente desenvolta de um sujeito que pensa, que conhecer e que diz: é, ao contrário, um conjunto onde se pode determinar a dispersão do sujeito e sua descontinuidade consigo" (FOUCAULT, 2005, p. 61). 
o que ela quer ser. acho que a última coisa que vem na cabeça é um condomínio de luxo. Não sou contra a verticalização, não é um dogma, mas existe espaço para a verticalização na cidade, e esse espaço não é aqui.

A partir de uma lógica policial, esse fala aponta para uma possível diferença de identidade de classe entre este entrevistado e os demais. No entanto, se tomarmos a ocupação como a criação de uma cena de dissenso, impossível identificar ali grupos particulares. Os sujeitos que formam uma comunidade dissensual escapam às identidades policiais, são sujeitos não-identitários. Trata-se exatamente dos "sem-parte", cuja existência está ligada a um processo de desidentificação com uma contagem mal-feita. O dissenso possibilita justo a conta dos não contados. Em outras palavras, a subjetivação política corresponde a um processo de desidentificação que redimensiona as formas de ser e estar no mundo. A fala a seguir denuncia justo uma contagem mal-feita pela lógica policial:

Aqui iria ser o local onde pessoas, uma minoria, iria comprar um espaço para morar e ter o privilégio de uma bela vista. A gente não tem direito a isso, porque a gente é pobre. Aí eu olho assim e... por que a gente não pode ter direito a isso? Por que a gente é pobre? Não, não. É a questão da igualde de direito, eu acredito na igualdade de direitos, eu acredito na transformação, isso vai demorar, é claro, mas meio sonho é que a gente tenha direito a isso, a gente tenha direito à cidade, que a gente possa ter direito a morar num local de qualidade, [...] a gente tem direito a ter moradia digna, aqui.

Embora no depoimento acima a entrevistada fale em igualdade de direitos, é bom lembrar que no pensamento de Rancière o dano fundado na política é distinto do litígio jurídico, o qual ocorre entre partes determinadas, regulando um acordo entre elas. A subjetivação política passa por um reordenamento do sensível o que não se limita à produção de novas leis, decretos e políticas públicas.

\section{Da dramaticidade das imagens e da sonoplastia}

Ainda segundo Rancière (1996), uma comunidade de partilha envolve o exercício de perceber o outro como interlocutor. Ou seja, é preciso inventar ao mesmo tempo o argumento e sua cena. O filósofo alerta que as cenas de dissenso promovem menos as formas de "ser em comum" do que "aparecer em comum". Segundo ele, "a aparência, e em particular a aparência política, não é o que esconde a realidade, mas o que a duplica, o que introduz nela objetos litigiosos, objetos cujo modo de apresentação não é homogêneo ao modo de existência ordinário dos objetos que nela são identificados" (ibid, p.107). Neste contexto, "a política é produzida por atos de linguagem que são, ao mesmo tempo, argumentações racionais e metáforas poéticas" (ibid, p.67). Portanto, a cena do dissenso mistura a dramaticidade da cena teatral com a racionalidade da cena argumentativa. 
Como expressão audiovisual da comunidade dissensual fundada com a ocupação do Cais, Vida Estelita comporta tanto o caráter racional quanto o dramático/poético da cena política. Nesse contexto, as falas dos entrevistados e as imagens que intercalam estas falas enfatizam o dissenso. A montagem instaura uma dualidade entre o bem, representado pelos integrantes do \#OcupeEstelita, e o mal, encarnado nas ações da polícia, do Governo do Estado e do consórcio. Por exemplo, logo após um dos entrevistados dar o depoimento de que não se arrepende de ter aberto mão de outras coisas para estar no Estelita, mesmo "apanhando", "levando porrada" e sendo xingado de "viado" por uma policial que ameaçou lhe pegar em outros protestos, surge na tela a imagem de uma inscrição feita no chão com restos de cartuchos disparados contra os manifestantes durante a reintegração de posse. A inscrição diz: "Prefeito Covarde". Na sequência, a bandeira de Pernambuco manchada de vermelho aparece pendurada no alto de um viaduto; depois surge uma faixa branca onde se lê "Nossos sonhos são à prova de balas". Fica caracterizada assim, não apenas em depoimentos, mas em imagens, o bem e o mal.

No instante em que esse mesmo entrevistado referenciado no parágrafo anterior está discorrendo sobre a "falta de sensibilidade" que é "comprar um apartamento numa torre de 40 andares, olhar a cidade de cima e vê Brasília Teimosa de um lado, e você do outro", aparece em primeiro plano, cortando horizontalmente de um canto a outro a tela, a imagem de um deck sob uma porção de água cinza; por trás dele, embarcações, casas e palafitas situam-se as margens de um braço de rio; do lado direto do quadro, sob o fundo de um céu também cinza, ergue-se imponente a figura fantasmática de um conglomerado de espigões. No momento em que muda o plano, as grades verticais do deck ganham proeminência. Em função da névoa que está mais cerrada, os espigões parecem surgir de forma ainda mais fantasmática por sob a cidade. Esta sequência acaba com um plano aberto onde se consegue enxergar mais uma vez o deck, a baía e a floresta de edifícios na outra margem do rio por cima das casas. Na hora em que a fala em off do entrevistado se encerra, esta imagem se mantém; um silêncio se instaura e perdura durante seis segundos, provocando a reflexão. Mais adiante, o som distorcido de um instrumento de metal acompanha as imagens em que o terreno aparece envolto por uma cerca de arame, vigiado por seguranças. Esta sonoplastia provoca uma sensação de angústia e mal-estar e se contrapõe à trilha usada para caracterizar o movimento, pois, neste último caso, trata-se de uma música ritmada, suave e alegre.

Quando outro entrevistado fala de "um modelo de cidade imposto de cima para baixo", duas torres são mostradas em plongé de baixo para cima, depois as mesmas torres são filmadas de frente, em plano geral. Há ainda imagens de pichações em muro com as palavras de ordem: "Fora Moura Dubeux", "A cidade é do povo", "Aqui não é Dubai", "Foda-se o capital", "O urbanista de Recife é o capital", "Tudo ilegal". Tais slogans respondem com violência a violência física e simbólica sofrida pelos integrantes do movimento. 


\section{Das novas formas de vida}

Todavia, o discurso que caracteriza a voz dos manifestantes não é só furor, também se reveste de poesia. Por exemplo, o vídeo abre com a imagem de uma espécie de lençol branco translúcido onde aparece parte de uma frase. Quando a câmera se movimenta, pode-se ler o enunciado por inteiro: "O amor no sentido ...da palavra". O pano branco exibe uma série de pichações e dizeres feitas pelos manifestantes. Por ser translúcido, o pano permite que se visualize pessoas movendo-se por trás dele. A imagem destes vultos encobertos diz muito sobre o ponto de vista a partir do qual a cidade os olha. Olha, mas não os vê. Como tratam-se dos "animais ruidosos" (RANCIÈRE, 1996), sua voz política não é ouvida. É preciso que o filme os descortine.

Vida Estelita eterniza em som e imagem as memórias, o jeito de viver e construir um comum daquela comunidade. Nesse contexto, o filme exibe cenas de gente acampada, de pessoas ajudando umas às outras a montar novas barracas no terreno do acampamento, gente arrumando e varrendo o local, pés descalços no chão batido, mãos cozinhando, cartazes indicando a hora das refeições, uma bicicleta recostada num canto, roupas e faixas penduradas por trás de uma placa onde está escrito "Vila Estelita". Tudo isso são signos de uma "Vida Estelita". Nesse sentido, o título do vídeo é muito feliz a medida que traduz o anseio por novas formas de viver que permeia a fala dos entrevistados, uma vida coletiva, partilhada.

A convivência em comunidade proporcionada pela ocupação tornou possível aos sujeitos acampados se manterem fora da ordem da família, do trabalho e do consumo. Fundaram uma comunidade eletiva. Se antes não existiam, ali nasceram desejos por novas formas de vida que privilegiavam o coletivo em detrimento do individual. Os depoimentos destacam isso:

Eu permaneci na ocupação depois que eu conheci as pessoas, depois que eu vim para cá e eu me senti acolhida por elas, me senti acolhida nas ideias, me senti participando da cidade.

Aqui a mudança é pra uma coisa que é coletiva. O coletivo no geral, o Recife. Tem uns que tão em casa e que dizem: "Ah! Isso é um bando de desocupado, não tem o que fazer". Aí, eu olho assim e digo: "É pra tu mermo e tu ainda diz que a gente é desocupado". Assim é uma coisa pro Recife, é uma coisa pra todo mundo.

A própria cenografia em que os entrevistados dão depoimento, sentados um ao lado do outro e o microfone passando de mão em mão, carrega em si mesma a ideia de união, de coletividade, de compartilhamento, de estabelecimento de vínculos e construção de um comum bastante presentes no discurso de todos eles. Mais ao final da conversa, inclusive, alguns jovens aparecem deitados, uns recostados sobre os outros, acentuando esta noção de proximidade e compartilhamento de ideias, ideais e desejos. Uma potência coletiva toma forma naquilo que se vê e ouve. 
Para quem está de fora, tudo isso pode tratar-se de um desejo utópico de juventude e de uma batalha perdida, mas para quem permaneceu acampado por 50 dias, compartilhou um mesmo espaço, dividiu tarefas, apanhou da polícia, resistiu, lutou e, apesar de tudo, conseguiu se alegrar, a experiência no Estelita foi algo único e transformador, como se vemos nas seguintes declarações:

Eu vim para cá e desde então a minha vida mudou totalmente.

... é muito válido para mim como pessoa. Vou levar essa experiência para

o resto da vida.

É possível enxergar a ocupação do Estelita como uma espécie de TAZ, "zona autônoma temporária"4 (BEY, 1985). Bey caracteriza uma TAZ como uma "máquina de guerra nômade" em que um "bando", colocando-se em especial contra o Estado, irrompe a cena política. Ele salienta que as TAZs não vislumbram soluções permanentes, mas irrupções temporárias. São acontecimentos extraordinários, posto que não acontecem levantes todos os dias, daí também sua vocação ao desaparecimento. Nada a lamentar, pois, à brevidade de sua duração se contrapõe a intensificação da vida cotidiana neste território. Como os depoimentos anteriores mostram, a vivência em uma TAZ pode dar sentido a toda uma vida. Pelbart (2013) afirma que estar junto e fundar uma comunidade implica ser afetado no corpo a corpo. Esta afetação mútua contamina, gera um movimento capaz de destravar a imaginação política e os desejos, dando nascimento ao novo, enfim, produz uma diferença. Por esta descrição, uma TAZ tem um potencial grande de se configurar como uma cena de dissenso onde se vê emergir a política.

\section{Dos impasses éticos}

O acampamento no Estelita funcionou como uma vivência política em que autonomia e liberdade ganharam potência máxima. Segundo os realizadores, muito contaminados por esta atmosfera e por um ideal anticapitalista radical de negação da vida produtiva regrada, normatizada, os entrevistados de Vida Estelita se expuseram muito em suas falas. Na percepção dos cineastas, os gestos disruptivos propostos pelos jovens acampados configuravam não apenas uma ameaça à ordem, mas a eles próprios. Na opinião dos diretores, devido ao seu alto grau de contestação e espontaneidade, os depoimentos registrados para as câmeras, e eternizados no filme, poderiam em alguma medida depor contra os entrevistados no futuro, tornando-os vulneráveis. Familiarizados com o poder que uma imagem tem de atuar contra ou a favor de alguém, sabendo da inevitável extinção do acampamento e, consequentemente, da volta de todos aqueles jovens aos seus respectivos cotidianos, os realizadores demonstraram preocupação com uma possível

4 Tradução em português da expressão: Temporary Autonomous Zone, TAZ. 
hiperexposição dos personagens. A solução foi "cortar na carne" e não ir tão a fundo nos modos de vidas que ali estavam sendo reivindicados e experienciados. A preocupação ética fez com que os sujeitos filmados fossem resguardados. Opiniões e relatos que adentravam em questões mais pessoais foram deixados de fora da edição final. Por conta do recuo que resolveram dar em relação ao caráter libertário das falas, os próprios diretores avaliam que o filme está aquém das experiências relatadas. Por outro lado, defendem que esta era a postura ética a ser tomada. Em sua autoavaliação, era necessário "proteger as pessoas daquilo que elas estavam falando".

Esta atitude abre um vasto campo de discussão sobre a representação do outro. No caso em análise, cabe questionar se ao deixar de fora os dizeres que apontam para diferentes modos de existência os realizadores não estariam demonstrando uma postura autoritária de deixar falar, mas não escutar? Não estariam camuflando, assim como faz a mídia hegemônica, as formas de vida em luta? Não estariam agindo contra as mutações do sensível?

Na exibição de Vida Estelita para os acampados, Marcelo, Pedro e Ernesto travaram o primeiro grande debate em torno da representação da alteridade. Na ocasião, foram questionados sobre os cortes no material bruto, mas, ao final das discussões, conseguiram a adesão da maioria. Nas respostas que deram aos presentes, além dos aspectos já citados sobre a hiperexposição de imagem, ressaltaram que "havia o filme que queriam fazer e o filme que precisava ser feito". Ou seja, do ponto de vista autoral gostariam de documentar toda aquela experiência libertária, mas, de uma perspectiva militante, percebiam que era arriscado abrir para a amplitude de reivindicações e desejos postos em pauta, pois, naquele momento, o \#OcupeEstelita enfrentava uma guerra midiática pesada.

Rocha (2015) explica que na disputa pelo apoio da opinião pública o alto capital cultural do MOE foi usado contra ele próprio. Segundo a autora, a condição de classe da maioria dos integrantes do movimento - estudantes universitários e profissionais cujas atividades muitas vezes se configuram em tarefas e projetos, e não pela lógica do "expediente", tornou-se o elemento central na construção da imagem dos manifestantes como "desocupados", "vagabundos", "maconheiros". Paralelamente, algumas das bandeiras contempladas pelo MOE, como moradia popular e defesa dos trabalhadores do comércio informal da região, não se mostraram suficientes para tecer uma aliança mais duradoura entre o \#OcupeEstelita e as classes populares, muitas vezes seduzidas pelas promessas de que o Novo Recife traria emprego e renda para a população local. Nesse contexto de poucas alianças, os realizadores resolveram abrir mão de pautas políticas outras que surgiram associadas à batalha pelo Cais $^{5}$.

5 Em 12 de junho de 2015, durante uma aula ministrada por João Vale Neto para alunos dos cursos de Cinema e Jornalismo da UFPE (alguns deles, inclusive, ex-integrantes da ocupação), Marcelo e Pedro julgaram o corte final de Vida Estelita "acanhado", "contido" "careta". Por um instante, cogitaram a possibilidade de ter feito outro filme, mais radical, mais pari passu com os relatos que ouviram. Mas, à medida que expunham para a plateia os dilemas éticos que enfrentaram durante a montagem, concluíram que "qualquer solução seria insatisfatória", reafirmando assim a decisão tomada anteriormente. 
Embora os realizadores sinalizem uma diminuição da potência política do vídeo quando da autorreflexão que fazem sobre o material bruto e aquele efetivamente posto para circular, defendemos que os discursos verbais e a própria mise-en-scène das personagens dão a ver aproximações e distanciamentos entre os sujeitos singulares que constituíram aquela coletividade. As falas abaixo, por exemplo, apontam dificuldades na construção de um comum:

... cada um tem um objetivo e era a partir desse objetivo que as pessoas decidiam ficar lá dentro, cada um com seu objetivo; claro... o objetivo maior da ocupação, mas o motivo de permanecer, de resistir, cada um tinha o seu ...

nós lidamos com situações inusitadas, aprendemos na prática o que é a vivência coletiva, você derruba muros, barreiras e aprende muito mais com o diferente do que com o que você já tá acostumado.

De nossa parte, não temos dúvida de que Vida Estelita opera um agenciamento memorialístico de grande potência política. Funciona como uma espécie de expansão para o campo audiovisual do dissenso provocado pela ocupação do Cais. Na vida e no vídeo, os sujeitos tomam posição e reivindicam um lugar de fala comum: o da militância em prol de uma configuração de cidade menos segregadora. O registro fílmico dá-nos a ver a política encarnada em corpos que desejam uma nova partilha do sensível, comprovando a afirmação de que "em nosso modo de imaginar jaz fundamentalmente uma condição para o nosso modo de fazer política" (DIDI-HUBERMAN, 2011, p. 60-1).

Cristina Teixeira Vieira de Melo é professora do Departamento de Comunicação Social e do Programa de Pós Graduação em Comunicação Social da UFPE. É doutora em Linguística pelo IEL/Unicamp.

cristinateixeiravm@gmail.com

\section{Referências}

BERNARDET, Jean-Claude. Cineastas e imagens do povo. São Paulo: Companhia da Letras, 2003. BEY, Hakim. TAZ, Zona Autônoma Temporária. São Paulo, Conrad, 1985.

DIDI-HUBERMAN. Sobrevivência dos vaga-lumes. Belo Horizonte: Editora UFMG, 2011.

FOUCAULT, Michel. A arqueologia do saber. Rio de Janeiro: Forense Universitária, 2005.

HALBWACHS, Maurice. A memória coletiva. São Paulo: Vértice, 1990.

NORA, Pierre. Entre Memória e História: a problemática dos lugares, In: Projeto História. São Paulo: PUC, n. 10, pp. 07-28, dezembro de 1993. 
MIGLIORIN, Cezar Ávila. Eu sou aquele que está de saída: dispositivo, experiência e biopolítica no documentário contemporâneo. Tese (Doutorado em Comunicação) - Universidade Federal do Rio de Janeiro, CFCH/ECO, 2008.

PELBART, Peter Pál. “Anota aí: eu sou ninguém”. Folha de S.Paulo, 13 jul. 2013.

RANCIÈRE, Jaques. O desentendimento: política e filosofia. São Paulo: Editora 34. 1996.

A partilha do sensível: estética e política. São Paulo: EXO experimental org; Editora 34. 2009. (2a . ed).

ROCHA, Maria Eduarda da Mota. O Movimento Ocupe Estelita: capital cultural e estrutura de sentimentos na interface entre a política e a cultura. Trabalho apresentado no XVII Congresso Brasileiro de Sociologia. 2015. (mimeo)

Artigo recebido em junho e aprovado em outubro de 2015. 